\title{
The Phylogenetic Roots of Cognitive Dissonance
}

\author{
Samantha West \\ University of Southern Mississippi, Gulf Coast
}

\author{
Stephanie E. Jett \\ University of South Alabama
}

Tamra Beckman and Jennifer Vonk

University of Southern Mississippi, Gulf Coast

\begin{abstract}
We presented 7 Old World monkeys (Japanese macaques [Macaca fuscata], gray-cheeked mangabey [Lophocebus albigena], rhesus macaques [Macaca mulatta], bonnet macaque [Macaca radiate], and olive baboon [Papio anubis]), 3 chimpanzees (Pan troglodytes), 6 members of the parrot (Psittacinae) family, and 4 American black bears (Ursus americanus) with a cognitive dissonance paradigm modeled after Egan, Santos, and Bloom (2007). In experimental trials, subjects were given choices between 2 equally preferred food items and then presented with the unchosen option and a novel, equally preferred food item. In control trials, subjects were presented with 1 accessible and 1 inaccessible option from another triad of equally preferred food items. They were then presented with the previously inaccessible item and a novel member of that triad. Subjects, as a whole, did not prefer the novel item in experimental or control trials. However, there was a tendency toward a subject by condition interaction. When analyzed by primate versus nonprimate categories, only primates preferred the novel item in experimental but not control trials, indicating that they resolved cognitive dissonance by devaluing the unchosen option only when an option was derogated by their own free choice. This finding suggests that this phenomenon might exist within but not outside of the primate order.
\end{abstract}

Keywords: cognitive dissonance, primates, nonhumans

Cognitive dissonance has been defined as the simultaneous representation of two disparate or dissonant beliefs or attitudes potentially causing psychological distress (Festinger, 1957). Since Festinger's (1957) early writings on this phenomenon, the topic has been widely studied in the field of psychology, but most of the research has focused on human adults. Adults apparently not only perceive dissonance in the form of psychological discomfort, but also attempt to resolve or alleviate these feelings by changing either their behaviors or their attitudes to be consonant with one another. For instance, much of the early research pioneered by Brehm $(1956,1959)$ found that people tended to devalue options they had not chosen from among options previously ranked equally preferable. In addition, both humans (Aronson \& Mills, 1959) and nonhumans (Friedrich \& Zentall, 2004; but see Armus, 2001) tend to rate activities and items as more valuable if they have worked harder to obtain them. We tend to take more pride in a promotion we feel was gained through hard work and dedication rather than one that was handed to us through favoritism and

This article was published Online First September 13, 2010.

Samantha West, Tamra Beckman, and Jennifer Vonk, Department of Psychology, University of Southern Mississippi, Gulf Coast; and Stephanie E. Jett, Department of Psychology, University of South Alabama.

The cooperation and support of the staff at the Mobile Zoo in Wilmer, $\mathrm{AL}$, are greatly appreciated. Special thanks to John Hightower, Bonnie Smith, and Joan M. Sinnott. All animal participants in this study were cared for according to the guidelines of the university IACUC and USDA.

Correspondence concerning this article should be addressed to Jennifer Vonk, Department of Psychology, University of Southern Mississippi, 730 East Beach Blvd., Long Beach, MS 39560. E-mail: jenvonk@gmail.com nepotism. We feel better about a high score on a test that we studied for rather than one we earned through cheating via copying from the student seated in front of us.

Notably, it appears that the perception of, and thus the need to alleviate, dissonance arises only if it is brought about by the individual's own free actions-not when behavior or attitudes can be explained by an external force. For example, Festinger and Carlsmith (1959) found that if participants were paid either $\$ 1$ or $\$ 20$ to convince others to participate in an experiment, those who were paid less later believed more strongly that the experiment was actually interesting. This is because the low rate of pay did not in and of itself justify their hard sales pitches. Those who were paid $\$ 20$ to convince others to participate did not need to justify their extrinsically motivated sales pitches. Thus, dissonance appears to be attributable to intrinsic motivations and free choices.

Despite the wealth of data on human adults, there has been little research regarding whether nonhuman organisms, or even human children, have the ability to reduce dissonance or even if they perceive it in the first place. In one notable exception, dissonance was created by giving preschool children a mild or severe threat not to play with an attractive toy (Aronson \& Carlsmith, 1963). The findings confirmed that the milder the threat, the less valuable the children later rated the toy. In line with Festinger and Carlsmith's (1959) findings with adults, if the threat was severe, the threat in and of itself was sufficient to justify the child's disinterest in playing with the toy; therefore, no dissonance needed to be resolved, and they could still think of the toy as appealing even though they avoided playing with it. However, if the threat was mild, the children needed to reevaluate their own attributions toward the toy to justify their lack of interest in playing with it. 
Until recently, the work on dissonance in nonhumans dealt with rewards, effort justification, and behavior extinction rather than focusing on changes in attitudes or values (e.g., Armus, 2001; Kacelnik \& Marsh, 2002). Previous research can be interpreted as consistent with hedonic contrast effects or physiological arousal as opposed to the experience of cognitive dissonance per se. Hedonic contrast effects can result when greater effort leads to an aversive behavioral state, causing the end reward to seem more desirable from that context, relative to the same reward following less effort (and a less aversive physiological state; Flaherty, 1996; Klein, Bhatt, \& Zentall, 2005). Hedonic contrast can also result when the chosen item becomes even more appealing by virtue of being chosen - the contrast between the two items becomes magnified by virtue of the choice, and the hedonic value of the chosen item is magnified, reducing the comparative value of the unchosen item (Sharot, De Martino, \& Dolan, 2009). Thus, the devaluing of the unchosen item results from a value (or greater physiological arousal) being associated with or assigned to the chosen item based on differential work effort to achieve it or a focus on additional information about the chosen item, not because of an internal cognitive decision that has been made regarding the options. One team of researchers has recently suggested that experiments requiring humans and nonhumans to exert differential effort for similar outcomes may be tapping into different cognitive phenomena than those requiring participants to place value on the outcomes themselves, a process more in line with what we typically think of as cognitive dissonance (Alessandri, Darcheville, Delevoye-Turrell, \& Zentall, 2008; Alessandri, Darcheville \& Zentall, 2008; Klein et al., 2005; Zentall, 2005).

Egan et al. (2007) recently designed an elegant and simple paradigm in line with Brehm's (1956) model of cognitive dissonance for use with both nonhuman primates (capuchins, Cebus apella) and human children (4-year-olds). They reasoned that, when given a choice between food items (capuchins) or stickers (children) that were previously deemed equally preferable, individuals would subsequently devalue items that they did not choose and thus would cease to choose that item when paired with previously unpresented items (also valued equally on prior tests) in the future. These researchers also reasoned that if the participants were not given a free choice, but, for some reason, were not allowed to choose one of the items in a control condition, they would not show the same tendency to devalue the item they were not able to select. Their predictions were borne out. It is interesting that the capuchins actually showed a preference for the items they were not able to select, whereas the children showed no preference in the control condition. Both species showed the predicted preference for the "novel" or unpresented item in the experimental condition.

The present study modifies and extends the Egan et al. (2007) investigation to previously unstudied species. Our goal was to determine whether other primate and nonprimate species would also shift their attitudes to fall in line with their decisions, enabling them to reduce dissonance. Because Egan et al. studied only a single New World primate species, we were interested to extend the paradigm to Old World primate species. We predicted that these groups, being more closely related to humans, would show the effects, although the findings of Egan et al. were driven by only two subjects (L. R. Santos, personal communication, Oct., 2007), so we were unsure how robust the findings would be in other more closely related species. In addition, we were interested to see whether nonprimate species would reveal evidence for dissonance. As much of the previous laboratory work had been conducted with bird species by Zentall's research group and with starlings by Marsh, Shuck-Paim, \& Kacelnik (2004), and there is much interest currently in how the cognitive abilities of some bird families compare with those of primates (Emery \& Clayton, 2004), we thought members of the parrot family were a logical nonprimate group to test. Whereas most of the focus has been on how the cognitive abilities of corvids compares with that of apes, parrots are often considered to be the "other intelligent bird" family; yet, little is known about their abilities, beyond that of a single African gray parrot named Alex (Pepperberg, 2006).

Furthermore, we wished to include a wider nonprimate group than just one taxonomic group before concluding whether dissonance might or might not extend outside the primate order. Given the nature of the paradigm we selected, we required subjects that could select the types of food rewards we were offering in a similar procedure. We also chose to include bears in the study because of their unique cognitive niche. Bears have a large relative brain size and are generalists in terms of their diet. This behavioral flexibility might suggest more cognitive flexibility, foresight, and planning, making them ideal candidates for studies of dissonance and other measures of cognitive abilities. In addition, canines are currently receiving much attention in part because of the domestication hypothesis (Hare, Brown, Williamson, \& Tomasello, 2002); therefore, bears are a natural outgroup as members of the same order that have not been domesticated, yet are highly trainable and easily motivated to perform in experiments. If both bears and parrots reveal evidence for dissonance, then it is clearly widely distributed in the animal kingdom, at least in the vertebrates, as these are all distantly related families. However, if neither parrots nor bears show evidence for dissonance and members of the Old World monkeys or chimpanzees do, then we would have reasonably strong evidence for concluding that dissonance might be limited to the primate order.

As in Egan et al. (2007), we first assessed the subjects' preferences for items belonging to different food categories and established two groups of three equally preferred items (hereafter triad $\mathrm{A}, \mathrm{B}$, and $\mathrm{C}$ and triad $\mathrm{D}, \mathrm{E}$, and F). In testing, the subjects were given a choice between two members of the triad (A and B) and subsequently were forced to choose between the item that was not chosen and the third, previously unpresented item from the triad (C). We also included a control condition. However, unlike Egan et al., we did not have the experimenter keep one of the items for herself, a factor that may have made that item appear more desirable, thus leading to the tendency for capuchins to prefer that item. Instead, we simply made that item inaccessible.

\section{Method}

\section{Subjects}

Several Old World monkey species were tested: two adult male Japanese macaques, Mojo and Chico (Macaca fuscata); one adult male gray-cheeked mangabey, Marcel (Lophocebus albigena); one adult male, Bubba, and one adult female, Baby, rhesus macaque (Macaca mulatta); one adult female bonnet macaque, Sophie (Macaca radiate); and one adult female olive baboon, Boo (Papio 
anubis). In addition, we tested three adult chimpanzees (Pan troglodytes): two males, Bonzo and Joe, one female, Corky; and four adult American black bears (Ursus americanus): two males, Dusty and Brutus, and two females, Elsie and Bella. Seven members of the parrot family (Psittacines); one female African gray, Smokey (Psittacus erithacus); one female blue and yellow macaw, Baby (Ara ararauna); one female Senegal parrot, Cookie (Poicephalus senegalus); one female red-shouldered Hans macaw, Tootie (Diopsittaca nobilis); one male green-winged macaw, Kid (Ara chloroptera); one male military macaw, Pirate (Ara militaris); and one female Indian ring-necked parakeet, Chief (Psittacula krameri manillensis) comprised the bird subjects. The African gray did not advance to testing. All participants were housed and tested at the Mobile, Alabama, Zoo. Some were group housed, and others were housed individually.

\section{Materials}

Food used included peanut M\&Ms (regular and richer colors labeled as "special M\&Ms," six and five colors, respectively); red, black, and green grapes; fruit-flavored parrot treats (in oval or half-moon shapes), Goldfish crackers; and low-sugar Fruit Loop or Cheerio cereal (six colors). Food types were selected because they differed in color but were identical in size and shape and potentially taste.

Food was offered by hand (two chimpanzees, bears, Cookie [parrot]), on a plastic tray (Corky [chimpanzee]), paper or plastic plate for the other parrots, or in feeders made of long white PVC pipes with white PVC cups on the end in which the visible food items were placed.

\section{Procedure}

Preference testing. To assess food preferences, we presented each subject with a series of choice tests among members of a single food category until two triads were obtained in which the subject demonstrated no appreciable difference in preference among the members of the triad. All members of a triad had to belong to the same food category (i.e., all had to be grapes, cereal, etc.). We considered preferences to be equivalent if the total number of trials in which each food item was chosen first differed by no more than two (for cereal and M\&Ms, in which there was a much larger number of total trials given) and was identical or differed by one (for grapes).

Preferences for grapes and bird treats were assessed across three to six 6-trial sessions in which each possible pairing of colors with each color presented once on each side occurred within sessions. Preferences for cereal and M\&Ms were assessed across 15 (regular $\mathrm{M} \& \mathrm{M}$ ) and nine (special M\&M) 6-trial sessions where pairings and side position of members of each pair were completely counterbalanced in blocks of five sessions for regular M\&Ms and across all nine sessions for special M\&Ms and bird treats. Thus, across food types, there were six presentations of each possible pair of food items. However, if at the completion of these preference tests, individual subjects did not show equivalent preferences for at least two triads of items, we continued preference tests until such preferences were obtained. Individuals received varying numbers of preference test sessions with different types of food on the basis of what initial preference tests revealed. Information about total number of preference tests given and subjects' choice of various items is presented in Table 1 .

Table 1

Food Preferences From Preference Testing and Triads Used in Testing for Each Subject

\begin{tabular}{|c|c|c|c|c|c|c|c|c|c|}
\hline \multirow[b]{2}{*}{ Subject } & \multirow[b]{2}{*}{ Family } & \multicolumn{4}{|c|}{ Triad 1} & \multicolumn{4}{|c|}{ Triad 2} \\
\hline & & Food & A & B & $\mathrm{C}$ & Food & $\mathrm{D}$ & $\mathrm{E}$ & $\mathrm{F}$ \\
\hline Mojo & Monkey & Grapes & R (14) & G (13) & $\mathrm{P}(15)$ & Cereal & Y (16) & G (15) & $\mathrm{O}(14)$ \\
\hline Chico & Monkey & Special M\&M & M (5) & $\mathrm{G}(6)$ & $\mathrm{T}(7)$ & Cereal & R (14) & B (14) & Y (15) \\
\hline Bubba & Monkey & $\mathrm{M} \& \mathrm{M}$ & R (14) & G (13) & Y (14) & Cereal & R (35) & G (36) & $\mathrm{O}(33)$ \\
\hline Baby & Monkey & Special M\&M & M (5) & G (6) & $\mathrm{T}(7)$ & Cereal & R (16) & $\mathrm{O}(17)$ & B (15) \\
\hline Marcel & Monkey & Grapes & R (11) & G (9) & $\mathrm{P}(10)$ & Cereal & R (14) & $O(15)$ & B (15) \\
\hline Sophie & Monkey & Special M\&M & G (13) & M (11) & BG (12) & Cereal & $\mathrm{O}(31)$ & B (29) & $\mathrm{P}(29)$ \\
\hline Boo & Monkey & Special M\&M & G (13) & $\mathrm{T}(11)$ & BG (12) & Cereal & O (29) & B (29) & $\mathrm{P}(28)$ \\
\hline Joe & Ape & Grapes & $\mathrm{R}(6)$ & $G(7)$ & $\mathrm{P}(5)$ & Cereal & R (17) & $Y(16)$ & B (17) \\
\hline Corky & Ape & Special M\&M & M (7) & $\mathrm{G}(5)$ & $\mathrm{T}(6)$ & Cereal & $\mathrm{R}(15)$ & $Y(15)$ & G (16) \\
\hline Bonzo & Ape & Special M\&M & M (9) & $\mathrm{T}(9)$ & BG (8) & Cereal & G (17) & B (17) & $\mathrm{P}(18)$ \\
\hline Brutus & Bear & Grapes & $\mathrm{R}(5)$ & G (7) & $\mathrm{P}(6)$ & Cereal & R (15) & G (15) & $\mathrm{O}(15)$ \\
\hline Bella & Bear & Cereal & G (16) & O (14) & B (15) & Cereal & R (15) & Y (15) & $\mathrm{P}(15)$ \\
\hline Elsie & Bear & Grapes & $\mathrm{R}(7)$ & G (5) & $P(6)$ & Cereal & R (16) & Y (16) & B (17) \\
\hline Dusty & Bear & Special M\&M & M (9) & G (8) & $\mathrm{T}(7)$ & Cereal & R (16) & $\mathrm{P}(17)$ & Y (18) \\
\hline Tootie & Macaw & Grapes & G(5) & $P(6)$ & $\mathrm{R}(7)$ & Cereal & $\mathrm{O}(9)$ & R (10) & B (10) \\
\hline Kid & Macaw & Oval treats & $\mathrm{O}(5)$ & Y (6) & G (7) & Cereal & B (11) & $\mathrm{R}(12)$ & $0(12)$ \\
\hline Chief & Parakeet & Goldfish crackers & R (7) & $\mathrm{O}(9)$ & $\mathrm{P}(8)$ & Cereal & $\mathrm{O}(11)$ & $\mathrm{R}(12)$ & G (13) \\
\hline Pirate & Macaw & Oval treats & $\mathrm{G}(11)$ & $\mathrm{O}(12)$ & $Y(12)$ & Cereal & $\mathrm{G}(9)$ & B (10) & $\mathrm{O}(10)$ \\
\hline Cookie & Parrot & Half moon & $\mathrm{Y}(11)$ & G (12) & R (13) & Cereal & $\mathrm{P}(11)$ & $\mathrm{O}(13)$ & $\mathrm{R}$ (14) \\
\hline Baby & Macaw & Half moon & $\mathrm{R}(9)$ & G (8) & $Y(7)$ & Cereal & $\mathrm{P}(12)$ & $\mathrm{Y}(12)$ & $\mathrm{O}(13)$ \\
\hline
\end{tabular}

Note. Letters indicate the color of foods used; For grapes, $\mathrm{R}=$ red, $\mathrm{G}=$ green, $\mathrm{P}=$ purple/black; for cereal, $\mathrm{R}=$ red, $\mathrm{O}=$ orange, $\mathrm{Y}=$ yellow, $\mathrm{P}=$ purple, $\mathrm{B}=$ blue, $\mathrm{G}=$ green; for $\mathrm{M} \& \mathrm{Ms}, \mathrm{Y}=$ yellow, $\mathrm{G}=$ green, $\mathrm{R}=$ red; for special $\mathrm{M} \& \mathrm{Ms}, \mathrm{M}=$ maroon, $\mathrm{G}=$ gold, $\mathrm{T}=$ teal, and $\mathrm{BG}=$ blue/grey. Numbers in parentheses indicate the frequency with which each subject chose that particular food item across all pairings presented during preference testing. 
Each session began with an experimenter centering the subject in front of the home enclosure. Food items were presented simultaneously on a plastic tray or in PVC feeders (as described above) with items placed equidistant on each side of the subject. For the bears and two of the chimpanzees, an experimenter familiar to the subjects held the food items in her hand on either side of the subjects' heads and allowed the subjects to take food items in their mouths. Food items were presented within the subjects' view until the subject attended to both items. Then the items were moved simultaneously to within the subjects' reach. A second experimenter, who was filming the choice for later reliability coding, recorded the subjects' first choice. On the occasional instance when subjects appeared to touch both food items simultaneously, we recorded as their choice the item that was first removed from the tray or feeder. Subjects were permitted to obtain both items from the tray or feeders during preference testing. Subjects received a maximum of 15 sessions per day, depending on appetite, three times a week over a period of several weeks until we had obtained two triads of equivalently preferred items for each subject.

One-choice training. One-choice training was used to prepare the subjects for testing in which they would be permitted to take only one of the two options presented. We selected two of the food choices that were not going to be used in testing for that particular subject and presented these two food choices in a single six-trial session in pairs in which each item appeared in a random order three times on each side, right or left. Subjects were then permitted to take one of the food items instead of both as in preference testing. As soon as subjects had one item, the experimenter withdrew the tray or feeder so that the other item could not be taken. This session was presented so that the subjects would understand that they were now permitted to have only their first choice, as it was critical for testing that the subjects understood that they were indeed making a choice.

Testing. Testing followed the same basic procedure as training with the following exceptions. Each subject was given 12 six-trial sessions consisting of three experimental or "choice" and three control or "nonchoice" trials in counterbalanced order across sessions. Both triads of equally preferred food items were used equally often on trials of both types, with each possible pairing used equally often on the first trial of each three-trial block within a session. On each session, one triad was used in the experimental trials and the other triad was used in the control trials.

On experimental trials, the first trial consisted of a choice between two items from one of the triads. Subject were allowed to choose only one of the two items. As soon as the subjects grabbed one item, the experimenter retracted the opposite feeder/hand or pulled the entire tray back (for Corky [chimpanzee] and the parrots). On the two subsequent trials, the experimenter presented subjects with the item not chosen in the first trial along with the previously unpresented third member of the triad, with side position counterbalanced across the two trials.

On control or no-choice trials, the first trial was identical to that of the choice condition, except that one of the two food items was visible but not accessible to the subjects, because one of the items was covered by a clear piece of tape. During this condition, the experimenter presented both options but retracted the inaccessible item as soon as subjects tried to grab it but failed. The experimenter then presented the subjects with two consecutive trials that involved the equally preferred unpresented member of the triad and the food item that subjects were not allowed to have in the first control trial. Again, side position of each option was counterbalanced within the session. Because each possible pairing of each triad was used on Trial 1 of the control trials, with position of each item counterbalanced, there were two control trials with each food item pairing. Thus, on one of these trials, one member of the pair was covered, and the next time that pairing was presented, the other member of the pair was covered. Which item was covered first was determined randomly. The covered item appeared on the right on half of the total control trials and on the left on the other half of all control trials.

To reduce the possibility that memory of the previous choice carried over into the next session, we separated sessions by approximately $30 \mathrm{~min}$ or more and no more than three testing sessions were conducted in a single day. Testing was distributed across 4 to 5 days over a 2-week period (2 months for the birds, which were tested less frequently).

All of the monkeys were tested using the feeders. The bears and two chimpanzees were given the food choices in the experimenter's hand, with one food choice in the left hand and the second food choice in the right hand. The experimenter presented the food on either side of the subjects' heads with food equidistant on either side and withdrew her hands as soon as the subjects turned their head and took one food item by mouth. On control trials, the inaccessible item was covered with tape across the experimenter's hand. The third chimpanzee and the parrots were tested with a tray or plate, as in preference testing.

\section{Data Coding and Analysis}

All testing sessions and most of the preference testing sessions were recorded on DVD for later coding. An experimenter recorded the choices of the subjects live during each trial. A second observer, who was not an experimenter, later watched all trials on DVD and independently coded the subjects' choices for the purposes of calculating reliability.

On preference testing, the rater coded from video 1,750 of the trials. This rater agreed with the online rater, who coded the trials live during testing for 1,624 of those 1,750 trials, leading to a Cohen's kappa value of 0.858 . The raters agreed on 1,165 of the 1,251 coded testing trials, leading to a Cohen's kappa value of 0.872 for testing. In cases of disagreement, the original online scored data sheets were used because it was sometimes difficult to discern the animals' choices from video; in cases of uncertainty, the online coder always verified with the other experimenter and immediately played the trial back from video at the time.

\section{Results}

\section{Preference Tests}

We first analyzed the subjects' preferences to obtain two triads of equally preferred food items. The frequency with which each 
subject chose different food items first across all pairs in which that item appeared is presented in Table 1.

\section{Testing}

The only subject that did not complete all 12 sessions was Baby, one of the rhesus macaques. She completed 10 experimental trials and 10 control trials.

Subjects' choices are depicted in Figure 1. A repeated measures analysis of variance comparing subjects' choice of the novel option in experimental versus control conditions based on whether subjects were primates or nonprimates revealed an almost significant interaction of subject classification and condition, $F(1,18)=4.61, p=06$. When separate $t$ tests were conducted comparing choice of the novel option under the two conditions (experimental vs. control) for primates and then for nonprimates, only for the primates was the test significant, $t(9)=2.27, p=.05,95 \%$ CI $[0.00,0.22]$.

Binomial tests were conducted to determine whether individual subjects chose the novel item significantly more than predicted by chance in experimental and control conditions separately. Only two subjects showed a significant effect at the individual level. Boo, an olive baboon, preferred the novel option in the experimental condition $(n=24, p<.001)$. Sophie, a bonnet macaque, also preferred the novel option in the experimental condition alone $(n=24, p=.02)$. This result is consistent with the findings of Egan et al. (2007), where only two capuchins individually chose the novel item significantly more than the unchosen item (L. C. Egan and L. R. Santos, personal communications, October 2007).

Of course, the results rest on the assumption that preferences within triads remained equivalent throughout testing for individual subjects. We assessed this by looking at subjects' choices on the first trial of each experimental trial on each of the 12 testing sessions, where presumably the choice was not influenced by an immediate prior choice. We could examine experimental trials only as subjects could take only one of the two options on control trials. These data appear in Table 2. It is evident that preferences were not always perfectly equivalent (i.e., 2, 2, 2), but in the vast majority of cases, preferences were distributed across all members of the triad $(1,2,3)$ in a relatively few number of trials $(n=6)$. There were only four cases (Sophie [bonnet macaque], Kid [macaw], Cookie [parrot], and Dusty [bear]) where one member of a food triad was not chosen at all on these trials. However, because Sophie was one of only two individuals that showed dissonance at an individual level, this finding does cast some doubt on the conclusion that her result is due to dissonance if her preferences were no longer equivalent throughout testing. Thus, it is possible that some subjects did not show dissonance because they had already adjusted their preferences by the time the last testing sessions were administered. However, to mitigate against the concern that the effect of dissonance was lost over time as preferences became unequal, we compared preference for the novel item between experimental and control trials for the primates only, and found that the effect was still significant, $t(9)=2.53, p=.01,95 \%$

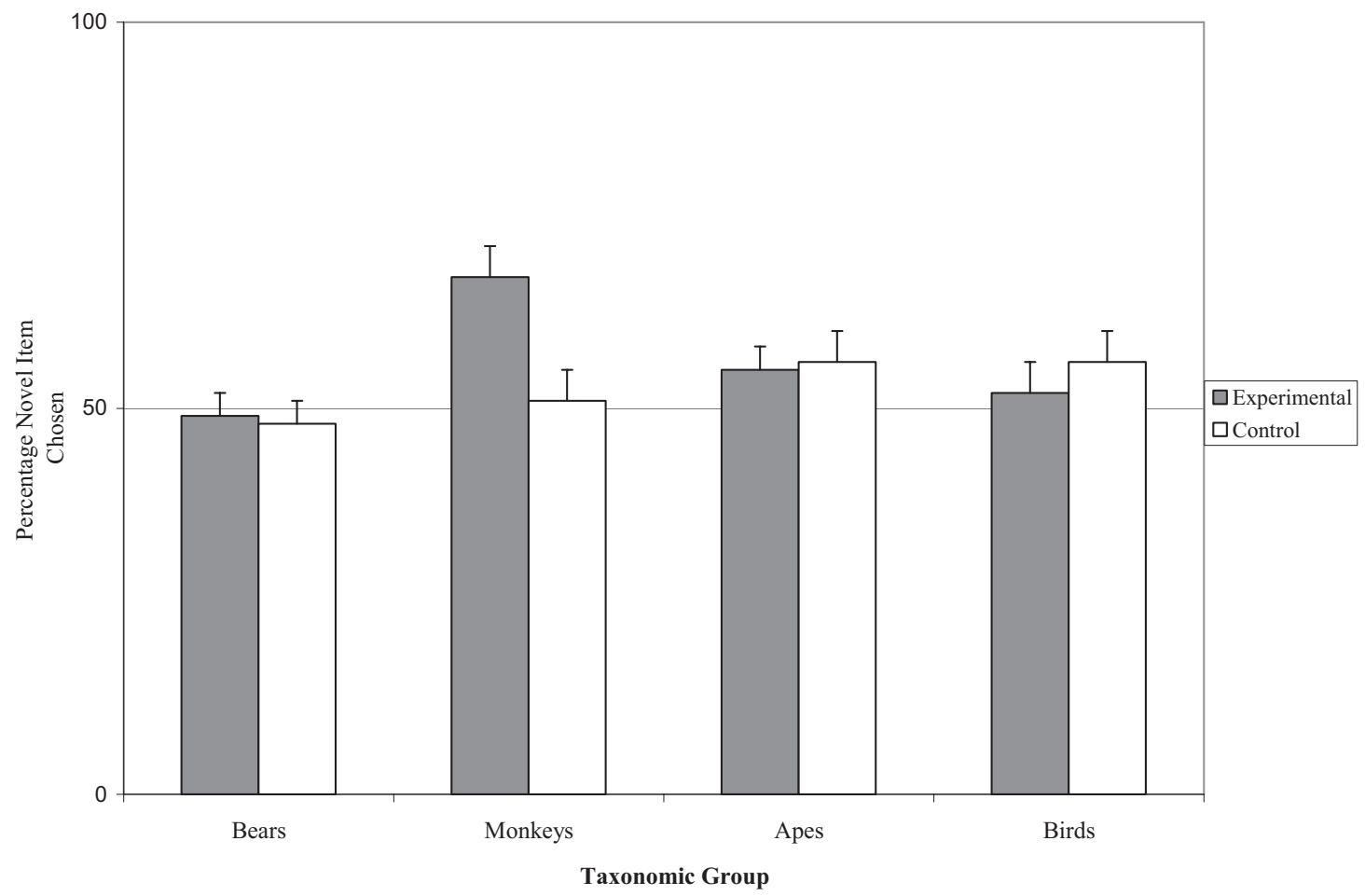

Figure 1. Subjects' mean preference for the novel item (with standard error) in both experimental and control conditions, by taxonomic grouping. 
Table 2

Trial 1 Data Indicate "Equivalence” of Preferences Across Testing Sessions Within Both Food Triads Used in Testing for Each Subject

\begin{tabular}{|c|c|c|c|c|c|c|c|}
\hline \multirow[b]{2}{*}{ Subject } & \multirow[b]{2}{*}{ Species } & \multicolumn{3}{|c|}{ Triad 1} & \multicolumn{3}{|c|}{ Triad 2} \\
\hline & & Food 1 & Food 2 & Food 3 & Food 1 & Food 2 & Food 3 \\
\hline Brutus & Bear & 2 & 1 & 3 & 1 & 2 & 3 \\
\hline Dusty & Bear & 3 & 3 & 0 & 2 & 2 & 2 \\
\hline Bella & Bear & 2 & 2 & 2 & 2 & 2 & 2 \\
\hline Elsie & Bear & 4 & 1 & 1 & 1 & 3 & 2 \\
\hline Sophie & Bonnet macaque & 2 & 4 & 0 & 2 & 2 & 2 \\
\hline Boo & Olive baboon & 3 & 2 & 1 & 3 & 2 & 1 \\
\hline Bubba & Rhesus macaque & 3 & 2 & 1 & 3 & 2 & 1 \\
\hline Baby & Rhesus macaque & 2 & 1 & 1 & 3 & 2 & 1 \\
\hline Mojo & Japanese macaque & 3 & 2 & 1 & 3 & 2 & 1 \\
\hline Chico & Japanese macaque & 1 & 2 & 3 & 1 & 2 & 3 \\
\hline Marcel & Grey-cheeked mangabey & 3 & 2 & 1 & 3 & 2 & 1 \\
\hline Bonzo & Chimpanzee & 3 & 2 & 1 & 2 & 2 & 2 \\
\hline Joe & Chimpanzee & 3 & 2 & 1 & 3 & 2 & 1 \\
\hline Corky & Chimpanzee & 3 & 2 & 1 & 3 & 2 & 1 \\
\hline Kid & Macaw & 4 & 2 & 0 & 3 & 3 & 0 \\
\hline Baby & Macaw & 3 & 1 & 2 & 3 & 2 & 1 \\
\hline Chief & Parakeet & 4 & 1 & 1 & 2 & 3 & 1 \\
\hline Tootie & Macaw & 3 & 1 & 2 & 2 & 2 & 2 \\
\hline Pirate & Macaw & 2 & 2 & 2 & 2 & 2 & 2 \\
\hline Cookie & Parrot & 2 & 4 & 0 & 2 & 3 & 1 \\
\hline
\end{tabular}

CI [0.03, 0.28]. The effect remained insignificant for nonprimates, $t(9)=0.27, p=.79$, nullifying the concern that they may have experienced dissonance initially, but failed to continue to display it as testing continued because of losing equivalence of preferences rather than losing the experience of dissonance.

\section{Discussion}

The aim of this study was to test the hypothesis that in the experimental testing trials, following the initial choice, the subjects would experience some form of dissonance and would devalue the unchosen food type. We also hypothesized that in the control testing phase, the subjects should not experience any form of dissonance following the presentation of two food items in which only one item was accessible because the freedom of choice had been taken away, as had the pressure to choose (dissonance). We also hypothesized that primates would show these effects and nonprimates would not. Both hypotheses were confirmed. Only primate subjects overall (and two monkeys individually) were more likely to prefer the novel option, $\mathrm{C}$, in the experimental condition than in the control condition, and preferred the novel option at above-chance levels in only the experimental trials.

Our findings are consistent with those from the previous study conducted with children and capuchins on which this experiment was modeled (Egan et al., 2007). Egan et al. (2007) found that children and capuchins were more likely to prefer the novel choice in the choice condition than in the no-choice condition. Our findings are also consistent with Aronson and Carlsmith (1963), who found that children changed their attitude toward a toy to fall in line with the punishment that would be given out. The current study and that of Egan et al. (2007) more specifically addressed dissonance because the subject's behavior should be affected only by its own dissonant choice. Choice of the novel option demonstrated that the subject changed its attitude regarding the food options following a choice that presumably caused cognitive dissonance.

We did not replicate the finding of Egan et al. (2007) that capuchins preferred the inaccessible item in the control trials. Those authors explained that somewhat surprising finding by suggesting that the monkeys may have believed the experimenters were keeping the "better" reward for themselves and thus assigned a higher value to the reward they were not allowed to have. In our design, it may have been less likely that the subjects perceived the inaccessible reward as being deliberately "kept" by the experimenter as the inaccessible food item was simply covered by a clear piece of tape that may have seemed unrelated to the experimenter's actions and intentions. Also, the same item was represented on the following two trials and was not taken away by the experimenter.

Whether dissonance was experienced in the same way by the few primates that appeared to reevaluate their assessments of previously valued items following choices, as it is by humans in prior studies, is beyond the scope of this single experiment. We would venture to suggest that it is unlikely to be the case. It seems unlikely that nonhumans feel the sort of psychological need to internally justify decisions post hoc that humans do. Although animals certainly experience distress about uncertain choices (Smith et al., 1995; Smith, Shields, Schull, \& Washburn, 1997), there is little evidence that they experience postchoice conflict, or in fact that they reflect on the past much at all, except for perhaps in the reconciliation literature (Flack \& de Waal, 2000). Even the need to reconcile with a past enemy does not necessarily indicate remorse or regret over a postaction, but merely the need to resolve conflict in a group or reaffirm bonds that could be beneficial in the future. 
Therefore, in the absence of a feeling of discomfort based on careful reflection about a choice or action being out of line with one's cognitions, what might drive the reevaluation of previously equivalently ranked items for a nonhuman? It seems likely that unchosen options might simply become associated less positively because they were present but not associated with the reinforcing actions of being consumed. However, Venkatraman, Ritchey, and Reeck (2009) suggested that "if stimuli are simple and closely matched (e.g., rating and choosing between different colored M\&Ms), it is unlikely that new information would come to mind during the choice or that any decision factors are differentially emphasized, and hence any revaluations would stem from a reduction of cognitive dissonance" (p. 18). Thus, they argued against a hedonic contrast explanation (as in Sharot et al., 2009) for the type of stimuli and paradigm used here, at least with human subjects. Although it may be more than hedonic contrast effects at play, it is more likely to be occurring at an automatic or unconscious level. However, it is notable that for the two subjects here that showed a significant preference for the novel option on experimental trials, they showed a slow and deliberate choice on those trials, whereas other subjects that failed to show the effect tended to choose rapidly, often with a side bias, indicating little consideration at all, a factor that may explain the limited individual effects in this study and the lack of effects in the chimpanzees, which tended to grab the food quickly and may have viewed the task as competitive and gave little thought to their choices. Boo in particular was striking to observe because she always selected options from the same side of the feeder, except on experimental trials when the novel option was on the opposite side-then she paused, appeared to think about her choice, and switched her typical preferred side choice! Anecdotally, which is always dangerous, it appears that Boo was carefully considering her choices, leaving the possibility open that, however dissonance is experienced, it happens consciously.

Future studies should investigate the ontogenetic origins of cognitive dissonance as well, and could examine infants 18 months to 3 years of age to see whether cognitive dissonance appears in the human species at a pivotal age in brain development. It could also be extended to older humans, for example, 60 to 80 years old, to determine whether dissonance dissipates as the brain ages.

The present results suggest that cognitive dissonance may be widespread within the primate order. Future work testing prosimians and other New World monkey species is presently lacking. In addition, there is very little known about cognition in general in nonprimates (with the exception of some avian species), although researchers are becoming increasingly interested in studying the cognition of nonprimate species such as dogs (Hare \& Tomasello, 2005) and cetaceans (Marino, 2003, 2004), particularly in the realm of social cognition. The particular topic of cognitive dissonance has not been widely studied outside the traditional rat and pigeon laboratory subjects. To our knowledge, ours is the first investigation of cognitive dissonance in a wide range of species, including bears and parrots, and the first using this free-choice paradigm with primates other than capuchins. We hope that the current study will increase others' interest in testing phylogenetically diverse species - those that share a recent part of our evolutionary history and those that have their own evolutionary path. The current findings are suggestive in that cognitive dissonance may be limited to the primate order, but more research is needed before such a conclusion can be firmly drawn.

\section{References}

Alessandri, J., Darcheville, J., Delevoye-Turrell, Y., \& Zentall, T. R.. (2008). Preference for rewards that follow greater effort and greater delay. Learning \& Behavior, 36, 352-358.

Alessandri, J., Darcheville, J., \& Zentall, T. R. (2008). Cognitive dissonance in children. Justification of effort or contrast? Psychonomic Bulletin \& Review, 15, 673-677.

Armus, H. L. (2001). Effect of response effort on the reward value of distinctively flavored food pellets. Psychological Reports, 88, 10311034.

Aronson, E., \& Carlsmith, J. M. (1963). Effect of severity of threat on valuation of forbidden behavior. Journal of Abnormal and Social Psychology, 66, 584-588.

Aronson, E., \& Mills, J. (1959). The effect of severity of initiation on liking for a group. Journal of Abnormal and Social Psychology, 59, 177-181.

Brehm, J. W. (1956). Postdecision changes in the desirability of alternatives. Journal of Abnormal and Social Psychology, 52, 384-389.

Brehm, J. W. (1959). Increasing cognitive dissonance by a fait accompli. Journal of Abnormal and Social Psychology, 58, 379-382.

Egan, L. C., Santos, L. R., \& Bloom, P. (2007). The origins of cognitive dissonance: Evidence from children and monkeys. Psychological Science, 18, 978-983.

Emery, N. J., \& Clayton, N. S. (2004, December 10). The mentality of crows. Convergent evolution of intelligence in corvids and apes. Science, 306, 1903-1907.

Festinger, L. (1957). A theory of cognitive dissonance, Evanston, IL: Row \& Peterson.

Festinger, L., \& Carlsmith, J. M. (1959). Cognitive consequences of forced compliance. Journal of Abnormal and Social Psychology, 58, 203-211.

Flack, D., \& de Waal, F. (2000). "Any animal whatever": Darwinian building blocks of morality in monkeys and apes. Journal of Consciousness Studies, 7, 1-29.

Flaherty, C. F. (1996). Incentive relativity. New York: Cambridge University Press.

Friedrich, A. M., \& Zentall, T. R. (2004). Pigeons shift their preference toward locations of food that take more effort to obtain. Behavioural Processes, 67, 405-415.

Hare, B., Brown, M., Williamson, C., \& Tomasello, M. (2002, November 22). The domestication of social cognition in dogs. Science, 298, 16361639 .

Hare, B., \& Tomasello, M. (2005). Human-like social skills in dogs? Trends in Cognitive Sciences, 9, 439-444.

Kacelnik, A., \& Marsh, B. (2002). Cost can increase preference in starlings? Animal Behaviour, 63, 245-250.

Klein, E. D., Bhatt, R. S., \& Zentall, T. R. (2005). Contrast and the justification of effort. Psychonomic Bulletin \& Review, 12, 335-339.

Marino, L. (2003). Cetacean brain evolution: Multiplication generates complexity. International Journal of Comparative Psychology, 17, 1-16.

Marino, L. (2004). Has scala naturae thinking come between neuropsychology and comparative neuroscience? International Journal of Comparative Psychology, 16, 28-32.

Marsh, B., Schuck-Paim, C., \& Kacelnik, A. (2004). Energetic state during learning affects foraging choices in starlings. Behavioral Ecology, 15, 396-399.

Pepperberg, I. M. (2006). Cognitive and communicative abilities of grey parrots. Applied Animal Behaviour Science, 100, 77-86.

Sharot, T., De Martino, B., \& Dolan, R. J. (2009). How choice reveals and shapes expected hedonic outcome. Journal of Neuroscience, 29, 37603765. 
Smith, J. D., Schull, J., Strote, J., McGee, K., Egnor, R., \& Erb, L. (1995). The uncertain response in the bottlenosed dolphin (Tursiops truncatus). Journal of Experimental Psychology: General, 124, 391-408.

Smith, J. D., Shields, W. E., Schull, J., \& Washburn, D. A. (1997). The uncertain response in humans and animals. Cognition, 62, 75-97.

Venkatraman, V., Ritchey, M., \& Reeck, C. (2009). Post-choice revaluation of hedonic preferences: Insights from functional imaging. Frontiers in Human Neuroscience. doi:10.3389/neuro.09.018.2009
Zentall, T. R. (2005). A within-trial contrast effect and its implications for several social psychological phenomena. International Journal of Comparative Psychology, 18, 273-297.

Received June 9, 2009

Revision received December 17, 2009

Accepted April 6, 2010

\section{Online First Publication}

APA-published journal articles are now available Online First in the PsycARTICLES database. Electronic versions of journal articles will be accessible prior to the print publication, expediting access to the latest peer-reviewed research.

All PsycARTICLES institutional customers, individual APA PsycNET ${ }^{\circledR}$ database package subscribers, and individual journal subscribers may now search these records as an added benefit. Online First Publication (OFP) records can be released within as little as 30 days of acceptance and transfer into production, and are marked to indicate the posting status, allowing researchers to quickly and easily discover the latest literature. OFP articles will be the version of record; the articles have gone through the full production cycle except for assignment to an issue and pagination. After a journal issue's print publication, OFP records will be replaced with the final published article to reflect the final status and bibliographic information. 